\title{
Farewell Editorial
}

With this issue, my term as Editor-in-Chief of the Canadian Journal on Aging comes to a close. My editorial in Volume 21, number 1, was entitled, "A Time of Opportunity for the Canadian Journal on Aging." In this, my last editorial, I offer some brief reflections on some of the accomplishments of the joumal over the past four years, accomplishments that lay the groundwork for new opportunities in the months and years ahead. It is wonderful to begin with good news about a success that brings new opportunities to the journal.

I am delighted to announce that the Canadian Journal on Aging has been accepted for inclusion in MEDLINE: Medical Literature, Analysis, and Retrieval System Online and its print counterpart, Index Medicus! MEDLINE offers all journal citations available in Index Medicus and much more. Both MEDLINE and Index Medicus are the U.S. National Library of Medicine's principal bibliographic citations databases. MEDLINE operates on-line, for free, and with no registration required, while Index Medicus has been available in print for 125 years. Inclusion in MEDLINE and Index Medicus is an exciting and important step forward for the journal. It is both a mark of the journal's quality and stature and a key to its future growth. These databases are widely used by researchers, practitioners, educators, students, and librarians, not only those in the health field but those in a wide variety of disciplines when the focus is on health-related issues. Articles published in the journal will now have much greater visibility and accessibility than in the past. This should encourage scholars to contribute their best work to the journal. Inclusion in these databases will help increase the number of manuscript submissions and enable us to reach our goal of publishing 10 articles per issue.

During my four-year term there have been a number of changes, all of which have, I hope, helped the journal move forward. All business and management functions were transferred to University of Toronto Press early in my term. That move meant the journal had direct access to a wide variety of in-house expertise in financial and business management, publicity, layout and design, and other areas. In the first year of my term, the joumal was successful in gaining funding from the newly created Canadian Institutes of Health Research's Institute of Aging. This new funding enabled the journal to expand in format and to publish more articles per issue, beginning with Volume 21, number 1 . New sections have been added, including "Brief Reports" and "Issues and Commen- taries". A process for electronic submission and review was instituted. Manuscript submissions have increased slowly but steadily, accelerating in the past year. The acceptance for inclusion in MEDLINE and Index Medicus will increase submissions further and, importantly, will induce scholars to submit their best work to the journal, thereby increasing the quality of the journal.

Acceptance for inclusion in MEDLINE and Index Medicus is particularly relevant in the field of aging, a multidisciplinary field in which health issues are among the central concerns. A glance at almost any issue of the journal reveals that the majority of articles fall under the rubric of health, broadly defined. There is no question that health-whether viewed at the individual or population level-is vitally important to individuals and societies. Not everything in the world, including the world of aging research, however, can be tidily reduced to a health issue. I would like to see more articles in the journal on many other topics of interest. These include, but are not limited to, topics such as family relationships, construction of biography, identity, ethnicity, historical perspectives on aging, and images of aging in art and literature. As well, and perhaps above all, I would like to see more attention to theory, both in individual articles and in the underpinnings of empirically based articles.

It has been a privilege and an ongoing learning experience for me to serve as Editor-in-Chief. I cannot think of another position I have held in my career in which I encountered as many challenges or learned as much as I have in the past four years. The position of Editor-in-Chief is very time-consuming, but it becomes consuming in less tangible, emotional ways as well. Whereas I began my term with a business-like attitude and a set of instrumental goals, over time I came to care deeply about the quality and success of the journal. I also grew increasingly aware of how many people besides the Editor-in-Chief contribute to and are essential to the journal's operations. As thrilled as I am, personally, by the general success of the journal and by its latest accomplishment, inclusion in MEDLINE and Index Medicus, I am deeply aware of how many people have contributed to bringing the journal to its current success. These include: the former Editors-in-Chief, each of whom made a distinctive contribution to moving the journal forward; the individuals who have served on the Editorial Board over the years; University of Toronto Press; 
and the many scholars who have supported the journal by submitting their work or by reviewing manuscripts.

I am indebted to those who have worked on the Editorial Board during my term: Marie Beaulieu, John Carlson, Ingrid Connidis, Carole Cohen, Elaine Gallagher, the late Ellen Gee, Thomas Hadjistavropoulos, Daniel Lai, Daphne Nahmiash, Joan Norris, Norm O'Rourke, Michel Preville, and Lucie Richard. I am grateful as well to Anne Marie Corrigan and Rosemary Clark-Beattie at University of Toronto Press; it has been a pleasure to work with them.

Finally, the financial support for the journal from the Social Sciences and Humanities Research Council of Canada and the Institute of Aging, Canadian Institutes of Health Research, is most gratefully acknowledged.
I know that the journal will thrive under the incoming Editor-in-Chief, Mark Rosenberg. I know, too, that he will benefit from the support of the strong Editorial Board that is currently in place.

Manuscrip t submissions should now be sent to:

Mark Rosenberg, Ph.D.

Editor-in-Chief, Canadian Journal on Aging

Department of Geography

Queen's University

Kingston, ON K7L 3N6

(rosenber@post.queensu.ca) 